\title{
Inhaler Use Technique in Chronic Obstructive Pulmonary Disease Patients: Errors, Practices and Barriers
}

Tareen Sanaullah ${ }^{1}$, Shereen Khan ${ }^{2}$, Aria Masoom ${ }^{3}$, Zahir K. Mandokhail ${ }^{4}$, Aisha Sadiqa ${ }^{5}$, Muhammad Irfan Malik 6

1. Pulmonary Medicine and Critical Care, FJ Chest Hospital, Bolan University of Medical and Health Sciences, Quetta, PAK 2. Pulmonary Medicine and Critical Care, Bolan University of Medical and Health Sciences, Quetta, PAK 3. Otolaryngology - Head and Neck Surgery, Bolan Medical Complex Hospital, Quetta, PAK 4. Internal Medicine, Bolan Medical Complex Hospital, Quetta, PAK 5. Gynaecology \& Obstetrics, Civil Provincial Hospital, Quetta, PAK 6. Pulmonology, Postgraduate Medical Institute/Ameer-ud-Din Medical College (AMC) Lahore General Hospital, Lahore, PAK

Corresponding author: Tareen Sanaullah, drsanatareen@gmail.com

\section{Abstract}

\section{Background}

Inhaled medications are the main therapeutic treatment of chronic obstructive pulmonary disease (COPD) and inhaler technique remained important that can increase medication efficacy, reducing dose and side effects. Poor inhaler technique is multi-factorial and the quality of inhaler technique has not previously assessed in Pakistan. We conducted a study to examine a range of competing factors that impact COPD patient willingness, practices, and preference in using their inhalers.

\section{Methods}

A cross-sectional of 765 patients with COPD were interviewed and assessed by qualitative questionnaires. Objective inhalation technique and steps assessment was performed; satisfaction, preferences, perception, and practice of different types of inhaler devices were evaluated at a single crosssectional visit at the study enrolment.

\section{Results}

The study included 765 participants of mean age 58.7 years ( $\mathrm{SD} \pm 7.8$ ); $32 \%$ males and $68 \%$ females. Almost all of the females were exposed to biomass fuel smoke exposure (99\%) and pipe (Huka) smokers 53\%, while most male participants were cigarette smokers ( $92 \%$ ). Only $6.3 \%$ of participants were able to perform correct steps of inhaler use, and few educated patients completed 7-steps. $66 \%$ of patients were using dry powder inhalers (DPI) inhaler devices and mostly performed the steps 1, 2, and 4 (98\%) correctly, while $44 \%$ who were using metered-dose inhalers (MDI) completed only steps 2 and 4 correctly (88\%). The majority of

Received 09/04/2020

Review began 09/13/2020 Review ended 09/17/2020 Published 09/21/2020

\section{() Copyright 2020}

Sanaullah et al. This is an open access article distributed under the terms of the Creative Commons Attribution License CC-BY 4.0., which permits unrestricted use, distribution, and reproduction in any medium, provided the original author and source are credited. participants reported the particular inhaler devices was prescribed by the visiting consultants (54\%). Interestingly, they were using two inhalers together (47\%) relieving symptoms of dyspnea (83\%) and cough (73\%). The inhaler use technique was demonstrated to most of the patients by the pharmacy salesman (38.4\%), while $15.8 \%$ reported that their doctors taught them the inhaler technique. $54.2 \%$ reported reason for poor adherence to inhaler use as they understand it might not work lately and $75.2 \%$ were not aware of any side effects associated with the regular use of an inhaler.

\section{Conclusions}

Poor inhaler technique is highly prevalent and the associated errors did not appear to be dependent on device type. Most of the participants had not receive proper training about the correct use and were not involved in decision making about the choice of inhaler device.

Categories: Family/General Practice, Pulmonology, Epidemiology/Public Health

Keywords: inhaler technique, inhalation errors, barriers, mdi, dpi, copd, practices

\section{Introduction}

Inhaled medications are the main therapeutic treatment of chronic obstructive pulmonary disease (COPD) with inhaler devices being the principal route for administering such treatments [1-2]. These treatments are given in the form of therapies that are emitted via nebulizers, pressurized metered-dose inhalers (pMDI), dry powder inhalers (DPI), or Soft Mist inhalers [3]. Each device has different operating, maintenance instructions, and successful use. A given inhaler requires that patients understand and maintain its proper use to ensure consistent optimal drug delivery into lower respiratory airways required by COPD patients. 
Poor inhaler technique remains an important and multi-factorial problem that can stem from the device itself, the patient, the healthcare provider, technology, and policy [4]. Many studies concluded that a large numbers of COPD patients do not use their inhaler devices correctly. Errors in device use may impact the effectiveness of the drug delivery, thereby leading to the sub-optimal treatment of COPD that causes multiple episodes of acute exacerbation which is associated with numbers of morbidities and mortalities [5]. After recognizing these particular factors and challenges, we can successfully train most patients to optimaly use inhalers with effective and repeated instruction [6].

Since COPD is a chronic condition, the therapeutic adherence of inhaler and optimal use in routine with the correct technique is the cornerstone in the management. It is therefore imperative to understand and quantify device-use errors so that patient interventions can be effectively introduced and new devices designed to avoid common errors associated with routine use of inhalers and to complete delivery of inhaled medication. It is important to recognize these particular factors and errors which are complex, but yet evidence suggests that these challenges can be addressed [7].

\section{Materials And Methods}

This cross-sectional study was conducted from January 2018 to December 2019 on patients with acute exacerbation of COPD admitted in the tertiary care FJ Chest hospital, a university teaching hospital in district Quetta, Pakistan.

The study participants were those patients admitted with acute exacerbation COPD, and interviewed by a qualitative questionnaire after obtaining an informed consent approved by the ethical committee. The interview was conducted on those patients who were discharged and ready to go home with an effective way to start a conversation about their medication including the inhaler technique. Seven steps of correct inhaler technique were explored by asking the patient “Can you show me how you use your inhaler in routine?”. Objective inhalation technique assessment was evaluated by looking at the number of steps completed by following the correct sequences of the steps that were recorded. Preferences with different types of inhalers were assessed by asking different questions like whether they had received information about the correct inhaler technique, their preferences, and the technique that had been checked by visiting doctors. Their socio-demographic characteristics, knowledge, and perceptions about their routine inhalers were recorded on the questionnaire. All these observations were recorded at a single cross-sectional visit of study enrolment.

\section{Results}

The study included 765 participants of mean age 58.7 years (SD \pm 7.8 ); 32\% males and $68 \%$ females. Almost all of the females were exposed to biomass fuel smoke exposure (99\%) and pipe (Huka) smokers 53\%, while most male participants were cigarette smokers (92\%) as shown in Figure 1.

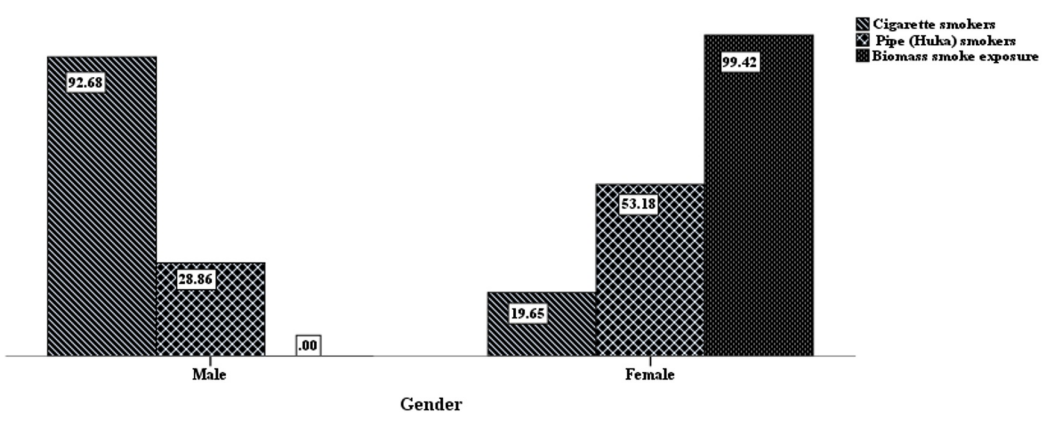

\section{FIGURE 1: Gender distribution of tobacco smoking and biomass smoke exposure}

Overall, 6.3\% of patients completed the seven correct steps of both metered-dose inhaler (MDI) and DPI. Few educated participants with a Master's degree and of younger age correctly performed almost seven steps (Figure 2). Both inhalers were being used for a mean duration of 5.3 years ( $\mathrm{SD} \pm 2.1$ ). MDI was used by $34 \%$ without spacer (55\%) and DPI was used by $66 \%$. Both MDI and DPI inhaler devices use were associated with multiple errors which included difficulties of pre-inhalation expiration (step-3), maximal inhalation (step5), and post inhalation breath-holding (step-6) (Table 1). 


\section{Cureus}

\begin{tabular}{|c|c|c|}
\hline Steps & Meter Dose Inhaler (MDI) & Dry Powder Inhaler (DPI) \\
\hline Step- $1^{1}$ & $(32.87 \%)$ & $(58.37 \%)$ \\
\hline Step $-2^{1}$ & $(13.78 \%)$ & (28.79\%) \\
\hline Step $-3^{1}$ & $(90.3 \%)$ & $(88.4 \%)$ \\
\hline Step $-4^{1}$ & $(0.5 \%)$ & $(0.3 \%)$ \\
\hline Step $-5^{1}$ & $(85.9 \%)$ & $(94.7 \%)$ \\
\hline Step- $6^{1}$ & $(89.1 \%)$ & $(87.6 \%)$ \\
\hline Step $-7^{1}$ & $(55.86 \%)$ & $(34.8 \%)$ \\
\hline \multicolumn{3}{|c|}{$\begin{array}{l}\text { 1. Jane Scullion, Monica Fletcher. UK Inhaler Group working group. 2018; 1-8. www.respiratoryfutures.org.uk/programmes/uk- } \\
\text { inhaler-group. } \\
\text { ntep1: Prepare the inhaler device Step2: Prepare or load the dose, Step3: Breathe out, fully and gently, but } \\
\text { not into the inhaler, Step 4: Place inhaler mouthpiece in the mouth and seal the lips around the mouthpiece, Step 5: Breathe in: pMDI } \\
\text { slow and steady, DPI: quick and deep, Step 6: Remover inhaler from the mouth and hold the breath for up to } 10 \text { seconds. Step 7: } \\
\text { Wait for a few seconds then repeat as necessary. }\end{array}$} \\
\hline
\end{tabular}

\section{TABLE 1: Errors associated with MDI \& DPI inhaler devices use}

Fifty-four percent of participants were not given the choice of inhaler by the visiting physicians. Interestingly, $47 \%$ were using a combination of both inhalers - DPI and MDI, thereby, reducing their symptoms of dyspnea by DPI in $83 \%$ of the participants; $73 \%$ reported cough relief by MDI use. $38.4 \%$ and $15.8 \%$ of participants reported that inhaler technique training was provided by pharmacy sales representatives and prescribing doctors, respectively (Table 2).

\begin{tabular}{|c|c|c|c|}
\hline \multirow{2}{*}{ Health Personals } & \multirow{2}{*}{ Inhaler Technique Teaching } & \multicolumn{2}{|c|}{ Patient's Inhaler Technique } \\
\hline & & Correct use & with Errors \\
\hline Pharmacy Salesman & 294 (38.4\%) & 09 (19\%) & $285(40 \%)$ \\
\hline Pharmacist & $201(26.3 \%)$ & $03(7 \%)$ & $198(27 \%)$ \\
\hline Doctors/Consultants & $121(15.8 \%)$ & $23(48 \%)$ & $98(14 \%)$ \\
\hline Staff Nurse & $93(12.2 \%)$ & 07 (14\%) & $86(11 \%)$ \\
\hline Post Graduate Residents & $40(5.2 \%)$ & $06(12 \%)$ & $34(5 \%)$ \\
\hline Spirometry Technician & $16(2.1 \%)$ & $0 \%$ & $16(3 \%)$ \\
\hline Total & 765 (100%) & $48(6.3 \%)$ & $717(93.7 \%)$ \\
\hline
\end{tabular}

TABLE 2: Health care personals involved in teaching inhaler technique and their association with inhaler use errors by patients 
Fifty-four percent of the participants reported poor adherence to regular use of inhalers as they understand that these inhalers are not effective lately to relieve their symptoms, while $33 \%$ were using their inhaler as a maintenance therapy which is quite a low figure. $75 \%$ were not aware of any side effects associated with the regular use of inhalers. Lastly, the participant's education level had an impact on the performance of correct steps, as seen in Figure 2.

\section{Discussion}

This cross-sectional study provides insights on inhalation devices types for delivery of COPD medications, including errors associated with its operation and factors to consider in matching a device to an individual patient. Currently, there are a large variety of inhalation devices available that presents numerous challenges both to patients and prescribing physicians as well [8]. Inhaled therapy represents the mainstay of COPD, therefore, appropriate use of inhaler devices is crucial to mitigate the risk of sub-optimal drug delivery and the subsequent risk of severe flare-ups, hospitalizations, and COPD related outcomes [9-10].

A previous systematic review has found that there has been no change in the types and number of errors reported over the past 40 years [10], and we evaluated errors associated with both DPI and pMDI as shown in Table 1 . Inhaler device adherence is relatively poor with approximately $25 \%-46 \%$ of patients remaining adherent to maintenance therapy [11] but in this cross-sectional analysis, the adherence was 33\% with poor technique showing the patients belief and trust on their prescribed inhaler relieved their subjective symptoms of dyspnea in $83 \%$ and cough in $73 \%$ of the participants. Previously, it had been observed that a comprehensive range of reasons for poor inhaler technique were noted, ranging from the device types, the patient preferences, the healthcare provider education on devices use technique, and the technology of inhalers [12]. In this certain group of COPD patients, we observed that most elderly patients could not handle their inhalers and preferred to use nebulizers (14\%) which does not involve perception to prepare and efforts requiring to complete the optimal seven steps [13]. Recent data show that $73 \%$ of patients consider their inhaler technique to be good or excellent, $86 \%$ of patients consider their inhaler easy to use, and compared with our study, 83\% participants showed confidence in their inhaler technique quite effectively and had no idea if it required more practice to improve the correct use. Most of the participants had not used their inhaler with all seven optimal steps wrongly handled the devices while performing the crucial steps 3, 5, and 6 for both DPI and MDI inhaler devices (Table 1).

To achieve optimal outcomes for patients with COPD, it is necessary to provide an inhaler that is simple and intuitive to use and is minimally affected by a patient's technique to ensure maximum efficacy [13]. Fiftyfour percent of our patients were not given options as to which type of inhaler they prefer with proper technique demonstration on their clinical visits to respiratory and general physicians. On the other hand, it has been observed that for the last couple of decades, the majority of patients have not been playing their role in using the given device correctly which is multi-factorial [8]. But in this observational analysis, most of the participants with poor technique were elderly as their perception was weak and found it difficult to understand the proper technique; they preferred using nebulizers 14\% [13]. A high proportion of patients inaccurately believe that their technique is adequate [14], and as in this study, 83\% of participants believed their technique is almost correct. This kind of attitude appears to create a disconnect between inhaler technique theory and practice, as mastery at the time of teaching does not translate into the maintenance of correct inhaler technique over time [15]. We recognize that, for the patient, there is a range of competing factors that impact their willingness, ability, and preference to using their inhalers [16-17], but we believe they can be trained successfully to use their inhalers with effective and repeated instruction [9-18].

Park et al. presented data on changing device switching from a DPI device to a pMDI on the persistence of medication use and effectiveness [19]. In our study, we observed this option was not given to switch from DPI to MDI as the participant's preferences for device selection was not inquired or valued by the visiting physician (55\%). Interestingly, it was revealed that DPI (66\%) is the most commonly used device as a reliever medication during exacerbation and for maintenance treatment, both DPI and pMDI were used together (47\%). Unfortunately, $50 \%$ to $81 \%$ of patients do not use their inhalational devices accurately, in particular, older patients preparing the dose in the wrong orientation which are the common errors [20-21]; in our study, most of the participants were older patients who could not perform the crucial step 3, 5 and 6 correctly. Few observational studies are more concerned about many health professionals do not use inhalers accurately [22-23] and their role being evaluated by a few countries [24]. Therefore, health care providers are not in a position to assess and coach patients' inhaler technique effectively as noted in Table 2; pharmacy salesman is the main trainer (38\%) who educates patients on inhaler technique but with major errors, while $16 \%$ reported that their prescribing doctors taught them the technique with less errors while performing their inhaler technique with optimal seven steps. There should be a consensus on who should provide the training to increase patient confidence, and whether patients should be allowed by clinicians to play a more extensive role in device selection. Health literacy is associated with poor use of healthcare services and these observations hold true for patients with COPD as well [25]. Since most of the participants were illiterate (86\%), their low literacy rate was associated with using a poor technique with multiple errors (Figure 2).

It is challenging to find the right inhaler device that tailors the patient's needs, preferences, and ability to use it correctly with minimal errors [26]. This widespread problem coupled with an awareness of device- 
specific and patient-specific variables affecting inhaler use, may improve clinical outcomes in the management of COPD patients [27-28]. We understand it requires an individualized approach, continued efforts, and repeated instructions with an appropriate device selection. Therefore, an effective training educational programme is required at the national level for proper inhaler use techniques that could minimize the risk of errors. We understand that inhaler handling with optimal steps training could improve adherence and clinical outcomes in COPD patients which could reduce the economic burden on the healthcare system of our developing country.

\section{Conclusions}

This study has shown that poor inhaler technique was highly prevalent among the participants and the errors did not appear to be dependent on inhaler device type (MDI vs. DPI). The participants were not involved in decision making about the choice of inhalation device and education level has an impact on the correct inhaler use. Both MDI and DPI inhaler devices were associated with multiple errors that included difficulties of pre-inhalation expiration, maximal inhalation, and post inhalation breath-holding steps. Therefore inhaler teaching and training is highly recommended with primary focus on the optimal steps errors to address the correct inhaler technique use in the management of COPD patients.

\section{Additional Information \\ Disclosures}

Human subjects: Consent was obtained by all participants in this study. Bio-Ethics Committee issued approval FJ-005/Jan-18/62354-BUMHS. Animal subjects: Bio-Ethics Committee Issued protocol number FJ005/Jan-18/62354-BUMHS. Conflicts of interest: In compliance with the ICMJE uniform disclosure form, all authors declare the following: Payment/services info: All authors have declared that no financial support was received from any organization for the submitted work. Financial relationships: All authors have declared that they have no financial relationships at present or within the previous three years with any organizations that might have an interest in the submitted work. Other relationships: All authors have declared that there are no other relationships or activities that could appear to have influenced the submitted work.

\section{References}

1. Molimard M, Raherison C, Lignot S, et: Chronic obstructive pulmonary disease exacerbation and inhaler device handling: real-life assessment of 2935 patients. Eur Respir J. 2017, 49:1601794. 10.1183/13993003.01794-2016

2. Sanchis J, Gich I, Pedersen S: Systematic review of errors in inhaler use: has patient technique improved over time?. Chest. 2016, 150:394-406. 10.1016/j.chest.2016.03.041

3. Melani AS, Bonavia M, Cilenti V, et al.: Inhaler mishandling remains common in real life and is associated with reduced disease control. Respir Med. 2011, 105:930-8. 10.1016/j.rmed.2011.01.005

4. Price D, Bosnic-Anticevich S, Briggs A, Chrystyn H, Rand C, Scheuch G, Bousquet J: Inhaler competence in asthma: common errors, barriers to use and recommended solutions. Respir Med. 2013, 107:37-46. 10.1016/j.rmed.2012.09.017

5. Singh D, Agusti A, Antonio A, et al.: Global strategy for the diagnosis, management, and prevention of chronic obstructive lung disease: the GOLD science committee report. Eur Respir J. 2019, 53:1900164. 10.1183/13993003.00164-2019

6. Perumal R, Leite M, van Zyl-Smit RN: The relationship between clinical trial participation and inhaler technique errors in asthma and COPD patients. Int J Chron Obstruct Pulmon Dis. 2020, 15:1217-1224. 10.2147/COPD.S249620

7. Miravitlles M, Soler-Cataluña JJ, Alcázar B, Viejo JL, García-Río F: Factors affecting the selection of an inhaler device for COPD and the ideal device for different patient profiles. Results of EPOCA Delphi consensus. Pulm Pharmacol Ther. 2018, 48:97-103. 10.1016/j.pupt.2017.10.006

8. Sriram K, Percival M: Suboptimal inhaler medication adherence and incorrect technique are common among chronic obstructive pulmonary disease patients. Chron Respir Dis. 2016, 13:13-22. $10.1177 / 1479972315606313$

9. Klijn SL, Hiligsmann M, Evers SMAA, et al.: Effectiveness and success factors of educational inhaler technique interventions in asthma \& COPD patients: a systematic review. NPJ Prim Care Respir Med. 2017, 27:24. 10.1038/s41533-017-0022-1

10. Lavorini F, Janson C, Braido F, Stratelis G, Løkke A: What to consider before prescribing inhaled medications: a pragmatic approach for evaluating the current inhaler landscape. Ther Adv Respir Dis. 2019, $13: 10.1177 / 1753466619884532$

11. Covvey JR, Mullen AB, Ryan M, Steinke DT, Johnston BF, Wood FT, Boyter AC: A comparison of medication adherence/persistence for asthma and chronic obstructive pulmonary disease in the United Kingdom. Int J Clin Pract. 2014, 68:1200-08. 10.1111/ijcp.12451

12. Ngo CQ, Phan DM, Vu GV, et al.: Inhaler technique and adherence to inhaled medications among patients with acute exacerbation of chronic obstructive pulmonary disease in Vietnam. Int J Environ Res Public Health. 2019, 16:185. 10.3390/ijerph16020185

13. Barbara S, Kritikos V, Bosnic-Anticevich S: Inhaler technique: does age matter? A systematic review. Eur Respir Rev. 2017, 26:170055. 10.1183/16000617.0055-2017

14. Darbà J, Ramírez G, Sicras A, Francoli P, Torvinen S, Sánchez-de la Rosa R: The importance of inhaler devices: the choice of inhaler device may lead to suboptimal adherence in COPD patients. Int J Chron Obstruct Pulmon Dis. 2015, 10:2335-45. 10.2147/COPD.S90155 
15. Collier DJ, Wielders P, van der Palen J, et al.: Critical error frequency and the impact of training with inhalers commonly used for maintenance treatment in chronic obstructive pulmonary disease. Int J Chron Obstruct Pulmon Dis. 2020, 15:1301-1313. 10.2147/COPD.S224209

16. Rogliani P, Calzetta L, Coppola A, et al.: Optimizing drug delivery in COPD: the role of inhaler devices . Respir Med. 2017, 124:6-14. 10.1016/j.rmed.2017.01.006

17. Price D, Fletcher M, van der Molen T: Asthma control and management in 8,000 European patients: the Recognise Asthma and Link to Symptoms and Experience (REALISE) survey. NPJ Prim Care Respir Med. 2014, 24:14009. 10.1038/npjpcrm.2014.9

18. Basheti IA, Armour CL, Bosnic-Anticevich SZ, Reddel HK: Evaluation of a novel educational strategy, including inhaler-based reminder labels, to improve asthma inhaler technique. Patient Educ Couns. 2008, 72:26-33. 10.1016/j.pec.2008.01.014

19. Park HS, Yoon D, Lee HY, et al.: Real-life effectiveness of inhaler device switch from dry powder inhalers to pressurized metred-dose inhalers in patients with asthma treated with ICS/LABA. Respirology. 2019, 24:972-9. 10.1111/resp.13559

20. Luczak-Wozniak K, Dabrowska M, Domagala I, Miszczuk M, Lubanski W, Leszczynski A, Krenke R: Mishandling of pMDI and DPI inhalers in asthma and COPD - repetitive and non-repetitive errors . Pulm Pharmacol Ther. 2018, 51:65-72. 10.1016/j.pupt.2018.06.002

21. Crane MA, Jenkins CR, Goeman DP, Douglass JA: Inhaler device technique can be improved in older adults through tailored education: findings from a randomised controlled trial. NPJ Prim Care Respir Med. 2014, 24:14034. 10.1038/npjpcrm.2014.34

22. Plaza V, Giner J, Rodrigo GJ, Dolovich MB, Sanchis J: Errors in the use of inhalers by health care professionals: a systematic review. J Allergy Clin Immunol Pract. 2018, 6:987-995. 10.1016/j.jaip.2017.12.032

23. Molimard M, Raherison C, Lignot S, et al.: Chronic obstructive pulmonary disease exacerbation and inhaler device handling: real-life assessment of 2935 patients. Eur Respir J. 2017, 49:1601794. 10.1183/13993003.01794-2016

24. Basheti IA, Salhi YB, Basheti MM, Hamadi SA, Al-Qerem W: Role of the pharmacist in improving inhaler technique and asthma management in rural areas in Jordan. Clin Pharmacol. 2019, 11:103-116. 10.2147/CPAA.S213271

25. Goris S, Tasci S, Elmali F: The effects of training on inhaler technique and quality of life in patients with COPD. J Aerosol Med Pulm Drug Deliv. 2013, 26:336-344. 10.1089/jamp.2012.1017

26. Alismail A, Song CA, Terry MH, Daher N, Almutairi WA, Lo T: Diverse inhaler devices: a big challenge for health-care professionals. Respir Care. 2016, 61:593-9. 10.4187/respcare.04293

27. Newman S: Improving inhaler technique, adherence to therapy and the precision of dosing: major challenges for pulmonary drug delivery. Expert Opin Drug Deliv. 2014, 11:365-378. 10.1517/17425247.2014.873402

28. Basheti IA, Obeidat NM, Reddel HK: Inhaler technique education and asthma control among patients hospitalized for asthma in Jordan. Saudi Pharm J. 2018, 26:1127-1136. 10.1016/j.jsps.2018.06.002 